\title{
IMPROVING LAND COVER MAPPING: A MOBILE APPLICATION BASED ON ESA SENTINEL 2 IMAGERY
}

\author{
M. T. Melis a*, F. Dessì a, P. Loddo b, C. La Mantia b, S. Da Pelo a, A.M. Deflorio b, G. Ghiglieri a, \\ B.T. Hailu c, K. Kalegele d, B. N. Mwasi e \\ a TeleGIS Laboratory, Dept. of Chemical and Geological Sciences, University of Cagliari, via Trentino 51, 09127 Cagliari, Italy \\ titimelis@unica.it \\ b Planetek Italia SRL, via Massaua, 1270132 Bari, Italy- lamantia@planetek.it \\ c School of Earth Sciences, University of Addis Ababa, College of Natural Sciences, P.O. Box 1176 Addis Ababa, Ethiopia - \\ binyam.tesfaw@aau.edu.et \\ d Nelson Mandela African Istitution of Science and Technology, P.O. Box 447, Tangeru Campus, Arusha, Tanzania - \\ kalegs03@gmail.com \\ e School of Environmental Studies, University of Eldoret P.O Box 1125 - 30100, Eldoret, Kenya - benmwasi@gmail.com \\ * Corresponding author
}

Commission III, WG III/1

KEY WORDS: Tanzania, Kenya, Crowd-generating data, Rift Valley, Fluoride, Sentinel

\begin{abstract}
:
The increasing availability of satellite data is a real value for the enhancement of environmental knowledge and land management. Possibilities to integrate different source of geo-data are growing and methodologies to create thematic database are becoming very sophisticated. Moreover, the access to internet services and, in particular, to web mapping services is well developed and spread either between expert users than the citizens. Web map services, like Google Maps or Open Street Maps, give the access to updated optical imagery or topographic maps but information on land cover/use - are not still provided. Therefore, there are many failings in the general utilization -non-specialized users- and access to those maps. This issue is particularly felt where the digital (web) maps could form the basis for land use management as they are more economic and accessible than the paper maps. These conditions are well known in many African countries where, while the internet access is becoming open to all, the local map agencies and their products are not widespread.
\end{abstract}

\section{INTRODUCTION}

The production of correct Land Cover maps is essential for many environmental applications. At present, land cover products originated from satellite data have a quality level closely related to the study area and to the ground validation datasets. Crowdsourced data represent an alternative and relatively new source of information that might improve maps production.

The diffusion of the Internet has encouraged the geographic information sharing (Goodchild et al, 2007) as well as the development and the availability of volunteered geographic information (VGI) tools (Flanaginì et al., 2008) in the Land Cover domain too (Fritz et al., 2009; Gengler et al., 2016; Salk et al, 2016). In the meanwhile, the circulation of locationenabled mobile devices has created a number of opportunities to involve citizens in field data acquisition (Fritz et al., 2017; Clark et al., 2011) and collection: citizens are sensors of location-based information (Goodchild, 2007).

Geospatial information is a good challenge for remote sensing science: map services allows users to reach remote sensing products as well as other map layers with a relatively simple usability.

This study is part of the the EU H2020 research Project FLOWERED (de-FLuoridation technologies for improving quality of WatEr and agRo-animal products along the East African Rift Valley in the context of aDaptation to climate change). FLOWERED project aims to develop technologies and methodologies to manage the risks associated with high Fluoride water supply in three study areas located in Ethiopia, Kenya and Tanzania. These sites have been chosen to analyse the local relationships between contaminated water and water supplies (Melis et al., 2017). These sites have been chosen to analyse the local relationships between contaminated water and water supplies.

In the framework of this project, a specific activity "Innovative Geo-Data system for the knowledge management"is working with the following general objectives:

- The development of a shared Geographic Information System based on open source repositories for data and metadata;

- The development of a land and water use databases based on an integrated use of satellite data and field data collection through the development of a mobile application dedicated to crowd- generating data;

- To support the dissemination activities of the results with specific web-GIS tools designed for the local, regional and international policy makers and institutions.

In this document, the following results are discussed:

- Land cover maps production through automatic algorithms based on a combination of object-based classifications and interactive rule based data fusion. Open satellite data from ESA Sentinel 1 and Sentinel 2 missions have been considered.

- FLOWERED GeoDBApp development and using in Tanzania and Kenya study sites.

- Limitations and issues related to the validation of the results.

- $\quad$ Future developments.

In this paper, the results of two field surveys in Tanzania and in Kenya are discussed. 


\section{STUDY AREA AND DATA SET}

\subsection{Study area}

As discussed in Melis et al., 2017, main objective of this study is the possibility to apply an action of crowd-generating data to improve the contents of new land cover maps, collecting information on water use in three areas of Africa affected by fluoride contamination. Fluoride is one of the most severe natural contaminants is. It was estimated (Fawell et al., 2006) that more than 260 million people worldwide consume drinking water with a fluoride content $>1.0 \mathrm{mg} / \mathrm{L}$. The issue of Fluoride contamination is of particular interest in many African countries, and in particular in the areas along the east African Sysytem (EARS). In order to discuss this issue in the EARS, three study sites in Tanzania, Kenya and Ethiopia have been chosen (Figure 1).

In this paper, the area of Arusha in Tanzania and the study site of Nakuru in Kenya have been considered. The study site in Kenya covers the catchment basins of Nakuru lake in the Nakuru County. Tanzania, neighbouring Kenya on the north and Indian Ocean on the east, is considered by the WHO to have communities, and respective livelihood, that are at high risk of being affected by fluoride-contaminated water (Fawell et al., 2006). These include the communities living along volcanic areas of the rift valley in the northern parts of the country around mountains Kilimanjaro and Meru.

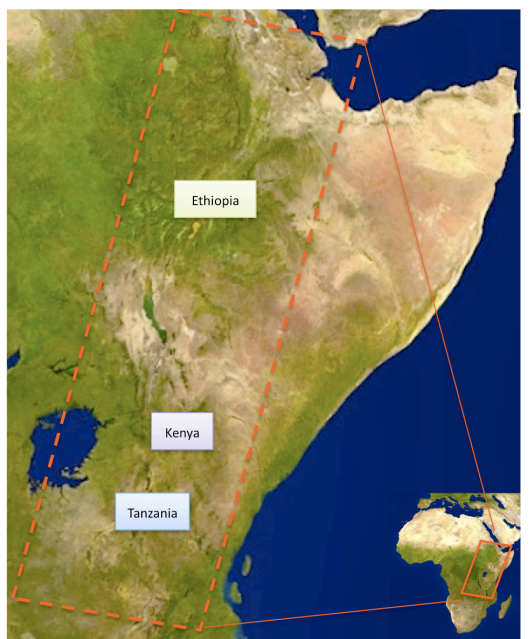

Figure 1. Localization of the three study areas.

\subsection{Data set}

\section{Satellite data}

Open satellite data from Sentinel 2 Multispecral Instrument (S2 MSI) has been considered as input base data for the implementation of automatic algorithms able to produce landcover maps on both test sites.

Composites images from S2 MSI has been processed with different rules regarding each country: (a) for Tanzania test case the composite processing step is restricted to the cloudy area of each image and it does not affect the whole image (as for the test sites in Kenya); (b) for Kenya test case the composite processing step involves the whole image coverage and not only the cloudy area (as for the test site in Tanzania). For this reason, the acquisition date of the image of Tanzania remains the same of the original input, while in Kenya the acquisition date makes reference to the acquisition time of all the input images which have contributed to the composite generation. In Table 1 the acquisition dates and the processing are listed.

\begin{tabular}{|l|l|l|}
\hline test site & acquisition date & processing type \\
\hline Tanzania & 20160204 & cloudcomposite.img \\
Tanzania & 20160723 & cloudcomposite.img \\
Tanzania & 20160802 & cloudcomposite.img \\
Tanzania & 20161021 & cloudcomposite.img \\
Kenya & 2016 -feb-apr & composite.img \\
Kenya & 2016-dic-gen & composite.img \\
Kenya & 2015-aug-oct & composite.img \\
Kenya & 2016-jun-jun & composite.img \\
Kenya & 2016-may-jul & composite.img \\
\hline
\end{tabular}

Table 1. S2 MSI images utilised in this study

\section{Open Street Map data}

OpenStreetMap (OSM) is a digital map database of the world built through crowdsourced volunteered geographic information (VGI). OSM is supported by the non-profit OpenStreetMap Foundation. Data collected by OSM is freely available for visualization, query, download and modification under open license.

OSM data has been considered in this study in order to improve maps details. Regarding this purpose, following datasets have been downloaded and partially modified:

Roads

Place Names

Administrative boundaries / Park boundaries Waterways

\section{SRTM data}

Elevation has been derived from SRTM 3Sec DEM data with spacing of $30 \mathrm{~m}$, performing a contour elaboration on the original grid dataset. SRTM has been preferred to ASTER GDEM2, as this last can be influenced by vegetation cover and cloud cover. Moreover, it is often altered by the presence of artefacts (Arras et al., 2017).

SRTM data are available free of charge, and the dataset covering study areas consists in a number of raster scene. Each scene has been mosaicked together in a new file on order to execute the contour line interpolation. After some attempts, a spacing of $100 \mathrm{~m}$ has been choose at the best compromise between legibility, usability and data contents for the print purpose. Contour lines interpretations leads to geomorphological recognition of landscape patterns.

\section{METHODOLOGY}

The methodological workflow consists of the following steps: (1) land cover map production; (2) geoData collection; (3) geoData storing; and (4) free access (Figure 2).

After a starting session, with the processes of authentication, users can utilise the app as input to collect data according three sessions:

-land cover ground truth data

-land cover validation data

-water use data.

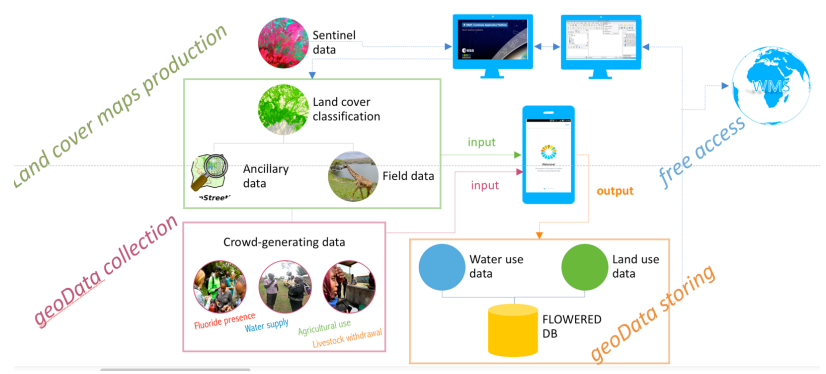

Figure 2. Methodological workflow. 
As planned, the app is dedicated to expert non-expert users. Using the app as experts, ground truth and map validation can be obtained (Figure 3).

As described in Melis et al, 2017, Land cover classification has been done by multi-temporal spectral indices (NDVI, NDWI, Brightness index) integrated with ancillary data. These maps were realised for the Tanzanian and Kenyan areas and uploaded through the app. In this way, they are available in online and in offline mode in the field.

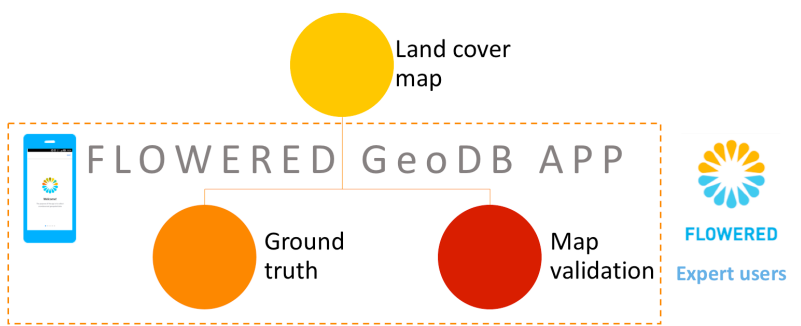

Figure 3. Data collected by expert users.

Citizens are requested to collect data mainly on land use and water use, viewing land cover maps on their smartphone device (Figure 4).

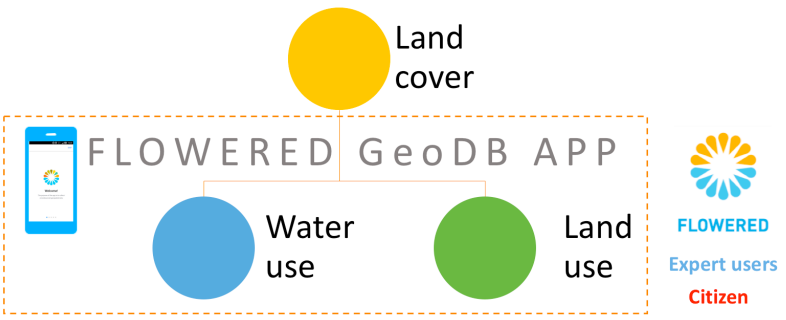

Figure 4. Data collected by expert users.

\section{RESULTS}

Two field surveys have been organized in Tanzania (July 2017) and in Kenya (March 2018) study areas in order to perform following activities:

- $\quad$ FLOWERED GeoDBapp general testing, also with local network and carriers;

- $\quad$ Land cover map check and validation;

- Collection of observations about water use and fluoride presence.

For both study areas, a total amount of 540 location points has been acquired, divided as referred in Table 2 .

\begin{tabular}{ccccc}
\hline \multicolumn{4}{c}{ Collected points (number) } \\
\hline $\begin{array}{c}\text { Study } \\
\text { area }\end{array}$ & Location & $\begin{array}{c}\text { Ground } \\
\text { truth }\end{array}$ & Validation & $\begin{array}{c}\text { Water } \\
\text { use }\end{array}$ \\
\hline Tanzania & 149 & 62 & 25 & 39 \\
Kenya & 391 & 141 & 150 & 46 \\
\hline
\end{tabular}

Table 2. Number of observation point collected referred to study areas

Furthermore, data collection has been finalized with a large number of georeferenced and compass oriented pictures, 322 for Tanzania and 578 for Kenya respectively.

Both surveys have geared across all the study area in order to acquire the biggest variety of land cover classes, as shown on figures 5 and 6 .

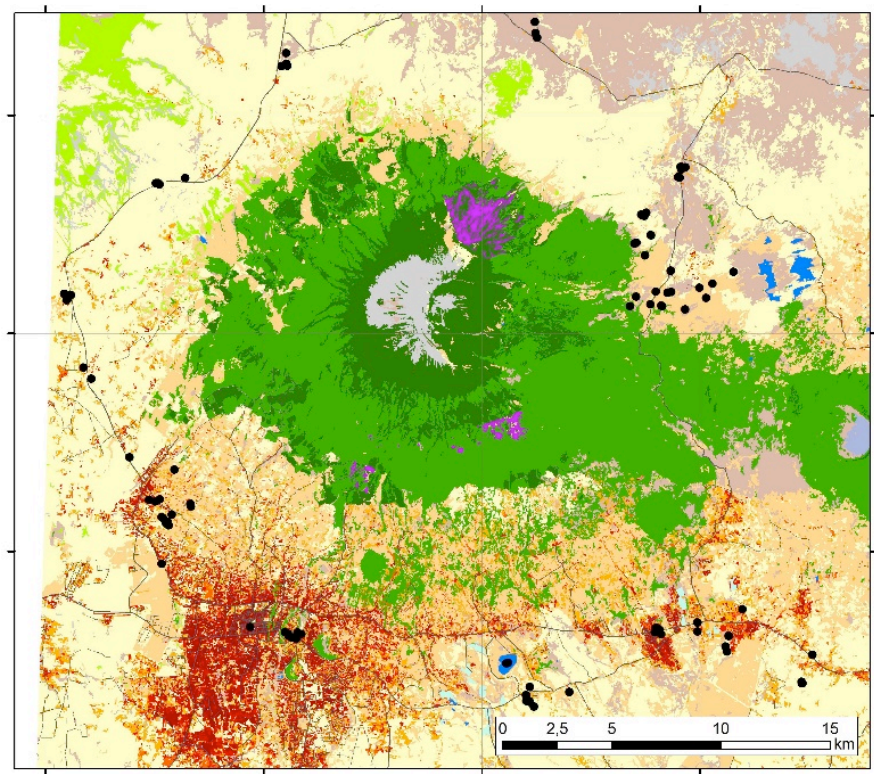

Figure 5. Position of observation points collected in Tanzania study area.

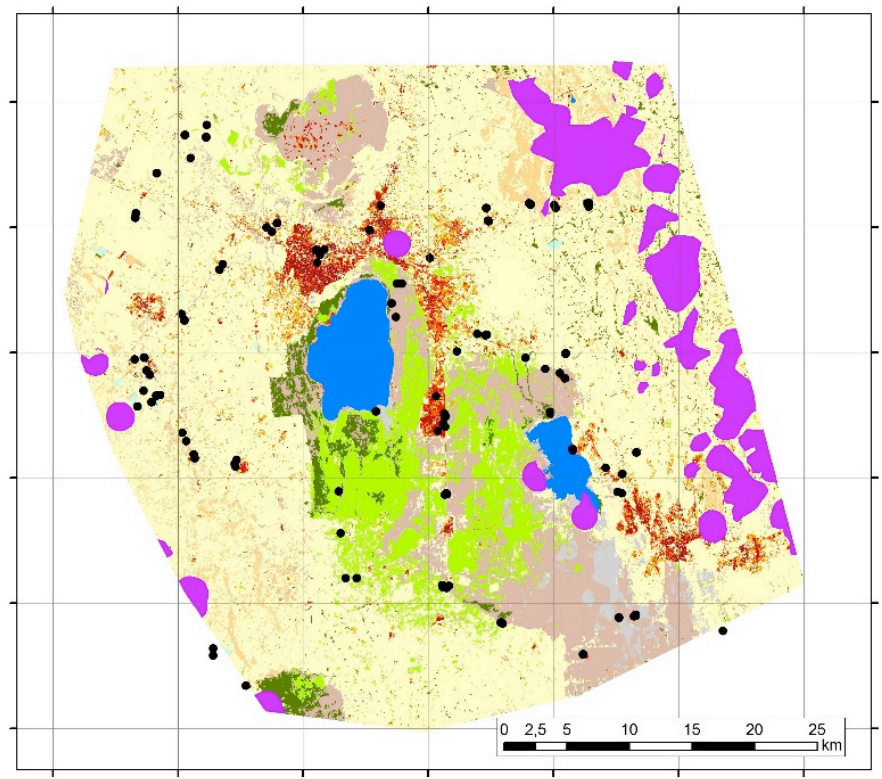

Figure 6. Position of observation points collected in Kenya study area.

During the survey, the team established contact with local people and authorities in order to introduce the FLOWERED project and in order to collect data especially regarding the water use and the fluoride presence.

The results of these activities are very positive as the use of smartphone is effective in these areas. The internet connection is good in the Kenyan study site, while in Tanzania some areas are not cover. In this case, the offline mode is mandatary. The final upload of data is very fast and the collaboration by local communities is complete. They demonstrated to be very interested to use a simple system to contribute to the issue of Fluoride contamination knowledge in order to be informed about it. 


\section{CONCLUSIONS}

With the aim to share with local community data on land use and water use, FLOWERED Project has developed an application for mobile, namely FLOWERED GeoDBApp. The app is dedicated to the collection of local geo- information on land use, water uses, irrigation systems, household features, use of drinking water and the other information needful for the specific knowledge of water supply (and then, the most suitable water remediation technique) involving local communities through participative approach with the local actors. All these data are directly linked to a land cover map based on the classification of ESA Sentinel2 data. This approach permits to correlate the land cover to one or more specific land uses, and specially to water uses.

In this way, the transform from land cover mapping to land use and, more specifically in this study, to water use would be guaranteed. Moreover, FLOWERED GeoDBapp has been created with the purpose to be ready for ground truth data collection and map validation. These actions are dedicated to expert users and are crucial for land cover mapping and for this purpose, the possibility to analyse the classified image in the device (in online and offline mode) has been proposed. The app has been developed with an open source SDK called Ionic Framework for iOS and Android systems, and it is available for download http://sharegeonetwork.floweredproject.org/geoportal/app.

Furthermore, this approach can be considered for updating land use data. As discussed in previous studies, changes in land use in the study areas are very quick as they are linked to local climate conditions. Moreover, as in other countries soil salinization, deforestation and forest fires are very common and can modify the land use of local communities (Afrasinei et al., 2015, 2017, 2018).

Data collected by the FLOWERED GeoDBapp will be available for the scientific community through a specific and dedicated web portal based on SHARE-GeoNetwork architecture (Melis et al. 2013; Melis et al. 2014; Mattavelli et al. 2016) with the sharing of knowledge based on open data philosophy.

\section{ACKNOWLEDGEMENTS}

This study is part of the Project FLOWERED that has received funding from the European Union's Horizon 2020 research and innovation programme under grant agreement N. 690378.

\section{REFERENCES}

Afrasinei G.M., Melis M.T., Buttau C, Bradd Jm, Arras C, Ghiglieri G., 2015. Diachronic analysis of salt-affected areas using remote sensing techniques: the case study of Biskra area, Algeria. In: Proc. SPIE 9644, Earth Resources and Environmental Remote Sensing/GIS Applications VI, $96441 D$ (October 20, 2015); doi:10.1117/12.2194998.

Afrasinei G.M. , Melis M.T., Buttau C., Arras C., A. Zerrim, Guied M., Ouessar M, Essifi B., Mongi Ben Zaied, Amor Jlali, Hanen Jarray, Ghiglieri G., 2017. Classification Methods for Detecting and Evaluating Changes in Desertification-Related Features in Arid and Semi-arid Environments. In Water and Land Security in Drylands Response to Climate Change. Editors: Mohamed Ouessar, Donald Gabriels, Atsushi Tsunekawa, Steven Evett. Springer. ISBN: 978-3-319-54020-7 (Print) 978-3-319-54021-4 (Online). DOI: 10.1007/978-3-31954021-4_23.
Afrasinei G.M., Melis M.T., Arras C., Pistis M., Buttau C., Ghiglieri G., 2018. Spatiotemporal and spectral analysis of sand encroachment dynamics in southern Tunisia. European Journal of Remote Sensing. Volume 51, 2018 - Issue 1. https://doi.org/10.1080/22797254.2018.1439343

Arras, C., Melis, M.T., Afrasinei, G.-M., Buttau, C., Carletti, A., \& Ghiglieri, G., 2017. Evaluation and validation of SRTMGL1 and ASTER GDEM2 for two Maghreb regions (Biskra, Algeria and Medenine, Tunisia). In M. Ouessar, D. Gabriels, A. Tsunekawa, \& S. Evett (Eds.), Water and land security in drylands. Springer. doi:10.1007/978-3-319-540214_24.

Clark, M.L.; Aide, T.M., 2011. Virtual Interpretation of Earth Web-Interface Tool (VIEW-IT) for Collecting Land-Use/LandCover Reference Data. Remote Sens. 2011, 3, 601-620

Flanagin, A.J.; Metzger, M.J., 2008. The credibility of volunteered geographic information. GeoJournal 2008, 72, 137148.

Fritz, S.; McCallum, I.; Schill, C.; Perger, C.; Grillmayer, R.; Achard, F.; Kraxner, F.; Obersteiner, M., 2009. Geo Wiki. Org: The Use of Crowdsourcing to Improve Global Land Cover. Remote Sens. 2009, 1, 345-354; doi:10.3390/rs1030345.

Fritz, S.; Fonte, C.C.; See, L., 2017. The Role of Citizen Science in Earth Observation. Remote Sens. 2017, 9, 357; doi: $10.3390 /$ rs9040357.

Gengler, S.; Bogaert, P, 2016. Integrating Crowdsourced Data with a Land Cover Product: A Bayesian Data Fusion Approach. Remote Sens. 2016, 8, 545; doi:10.3390/rs8070545

Goodchild, M.F.; Fu, P.; Rich, P., 2007. Sharing geographic information: an assessment of the geospatial one-stop. Ann. Assn. Amer. Geogr. 2007, 97, 250-266.

Goodchild, M.F., 2007. Citizens as sensors: the world of volunteered geography. GeoJournal 2007, 69, 211-221.

Mattavelli M., Strigaro D., Frigerio I., Locci F., Melis M.T., De Amicis M., 2016. The IDB: an ice core geodatabase for paleoclimatic and glaciological analyses. Geografia Fisica e Dinamica Quaternaria 39 (1), 59-68, doi: 10.4461/ GFDQ. 2016.39.6.

Melis M. T., Dessì F., Locci F., Bonasoni P., Vuillermoz E., 2013. Share Geonetwork: a web-service platform for environmental data sharing. Proc. SPIE 8795, First International Conference on Remote Sensing and Geoinformation of the Environment (RSCy2013), 87951V (August 5, 2013); doi:10.1117/12.2027602.

Melis M.T., Locci F., Dessì F., Frigerio I., Strigaro D., De Amicis M., Vuillermoz E., 2014. NextData Project: development of a web system for climate and paleoclimate data sharing. Rendiconti Online della Società Geologica Italiana, Vol. 31., doi: 10.3301/ROL.2014.140.

Salk, C.; Sturn, T.; See, L.; Fritz, S., 2016. Local Knowledge and Professional Background Have a Minimal Impact on Volunteer Citizen Science Performance in a Land-Cover Classification Task. Remote Sens. 2016, 8, 774; doi: $10.3390 /$ rs 8090774 . 